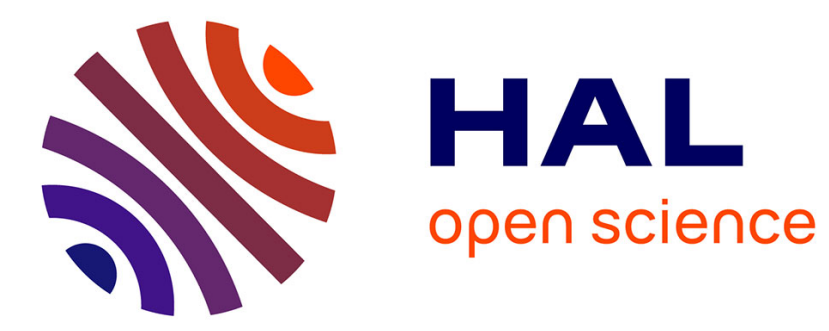

\title{
Using Interaction Analysis to reveal Self-Regulated Learning in Virtual Communities
}

\author{
Giuliana Dettori, Donatella Persico
}

\section{To cite this version:}

Giuliana Dettori, Donatella Persico. Using Interaction Analysis to reveal Self-Regulated Learning in Virtual Communities. EC-TEL 2007,Crete, Greece, September 17-20, 2007, 2007, Greece. pp.3-13. hal-00197205

\section{HAL Id: hal-00197205 \\ https://telearn.archives-ouvertes.fr/hal-00197205}

Submitted on 14 Dec 2007

HAL is a multi-disciplinary open access archive for the deposit and dissemination of scientific research documents, whether they are published or not. The documents may come from teaching and research institutions in France or abroad, or from public or private research centers.
L'archive ouverte pluridisciplinaire HAL, est destinée au dépôt et à la diffusion de documents scientifiques de niveau recherche, publiés ou non, émanant des établissements d'enseignement et de recherche français ou étrangers, des laboratoires publics ou privés. 


\title{
Using Interaction Analysis to reveal Self-Regulated Learning in Virtual Communities
}

\author{
Giuliana Dettori, Donatella Persico \\ Institute for Educational Technology - Italian National Research Council, Italy \\ dettori@itd.cnr.it, persico@itd.cnr.it
}

\begin{abstract}
Aim of this paper is to analyse whether Interaction Analysis can help investigate the practice and development of Self-Regulated Learning (SRL) in Virtual Learning Communities (VLC). Interaction analysis is increasingly used to study learning dynamics within online activities. It proceeds by searching expressions that reveal the aspects under study in the written messages exchanged by the learners. To this end, we devised and classified a number of indicators suggesting the existence of self-regulated events, and tested this approach on the online component of a blended course for trainee teachers. We analysed the messages exchanged by a group of learners in two modules of the course and compared the results with those of a previous study carried out with more traditional methods. The similarity of the results obtained by the two approaches suggests that Interaction Analysis is an effective, though rather labour-intensive, way to study SRL in VLCs.
\end{abstract}

Keywords: Self-Regulated Learning, Virtual Learning Communities, Teacher Training, Computer Supported Collaborative Learning, quantitative content analysis of interactions.

\section{Introduction}

Virtual Learning Communities (VLC) and Computer Supported Collaborative Learning (CSCL) allow the implementation of collaborative learning in online environments. Both use computer-mediated communication, mostly textual and asynchronous, to support group interactions at a distance among trainees, with the guidance of facilitators and tutors. Research into this socio-constructivist approach to learning has been increasingly using Interaction Analysis (IA) to investigate and understand the learning dynamics that take place CSCL environments. IA is based on the detection of phrases and expressions that reveal the aspects under study in the written messages exchanged by the learners. It therefore combines qualitative analysis of individual messages with quantitative elaboration of results. This method takes advantage of the non-intrusive capability of technology to track events (such as students messages) during the learning process, therefore potentially replacing or at least complementing more intrusive ways for gathering data. For this reason, IA is considered a powerful source of data, although it often requires human intervention, both in the analysis phase and in the interpretation of data

Studies in IA may look at different types of content [11]. Manifest content is easily observable in that it concerns visible and objective communication features. An example of manifest content is the number of times students address each other by name. In general, manifest content can be spotted by looking for some particular expressions and hence the coding process is relatively easy to automate. In some cases, however, the aspects under study cannot not be directly connected with specific expressions, but rather they need to be inferred on the basis of the analysed texts. IA in these cases relies on the detection of "latent variables" [10]. Detection of latent content is much more complex, in that it requires interpretation and application of some heuristics in the analysis of the messages. Manifest content can obviously be investigated with more objectivity and can be automated more easily. Nevertheless, latent content is worth attention in that it is often related to interesting research questions. In this paper, we claim that Self-Regulated Learning (SRL) is one of those fields of study where it is necessary to handle latent content.

Self-Regulated Learning (SRL) is one of the fields of study where it is useful to handle latent content. The term SRL identifies a set of cross-curricular competences allowing the learners improve their learning efficacy, as well as to apply and adapt the 


\section{Addendum Proceedings EC-TEL 2007}

acquired knowledge across different subjects. The research in this field investigates the pedagogical, behavioural, emotional, motivational, cognitive and meta-cognitive aspects involved when students learn to control their own learning processes $[14,15]$.

The relationship between SRL and CSCL is quite complex because effective use of CSCL environments appears both to require and to improve the ability of learners to self-regulate their own activity [6]. In CSCL, SRL competence and, in particular, meta-cognitive skills are often among the explicit or implicit objectives of the learning process. This is primarily due to the fact that learners who are new to this training method usually lack some of the meta-cognitive and self-direction skills that are needed to take full advantage of this learning approach, and therefore well designed courses try to stimulate learners in this respect. Moreover, learning in such context is mostly based on textual interaction, and this supports reflection not only on content knowledge but also on the learning process itself. As a consequence, such learning environments appear to foster SRL by putting into play several SRL-related skills, so that CSCL environments may be regarded as promising for its development $[1,9,11]$ At the same time, SRL appears necessary to make good use of learning experiences within VLCs not only because students need to organize time and pace of their learning process, but also because collaborative activities entail negotiating objectives, strategies and concepts with peers.

Research into SRL is currently carried out by analysing students' actions, that is, by trying to understand to what extent they set their goals, plan their learning and evaluate their progress, practice meta-cognition and self-reflection. It is not surprising, therefore, that Interaction Analysis is rarely applied to the study of SRL in VLCs, in that it requires the detection of latent content. Currently, investigation of SRL mostly relies on interviews where learners are requested to describe, ex-post, the strategies and methods they used during the learning process, or on questionnaires aimed at eliciting information from the learners' about their strategic planning and the other choices made during the leaning process. It should be noted that even these traditional methods of analysis are not able to directly measure the practice of SRL, but they try to deduce its presence from students actions, their opinions and their verbalisations concerning the learning process. This confirms the intrinsic complexity of this field of analysis.

This paper proposes to use IA to investigate the practice of SRL in VLCs, as a possible way to rely on data of different nature, hence offering the possibility to complement studies based on traditional methods. It is true that the outcomes of IA are affected by coders' discretionary, since SRL can be detected only by means of latent variables, but they depend less on students' discretionary, since they are directly based on the students' actions, i.e. the messages they sent, rather than their interpretations of the learning events.

In the following, we propose a set of indicators of SRL and report on their application in an exploratory study carried out on the online component of a blended teacher training course in Educational Technology. The outcomes of the study are discussed and compared with those of a previous study carried out with more traditional means. Aim of this paper is to evaluate the feasibility, reliability and costeffectiveness of the approach proposed, in view of a possible application on a larger scale.

\section{Detecting SRL indicators}

We can define Self Regulated Learning as a learning process where students master and deliberately control their own learning, by setting their goals, by choosing their learning strategies, by reflecting on their own learning and by evaluating their progress and consequently adapting their strategies, with a cyclic process. Selfregulated learners are often intrinsically motivated and see learning as a proactive activity; in other words, they actively control rather than passively endure the learning process. They usually have a good degree of self-efficacy and are able to apply and adapt the acquired knowledge across different subjects.

The study of SRL in online environments by means of AI is complicated by the fact that, despite the variety of approaches that have been applied to investigate the nature and extent of SRL [16], this competence has always been characterised in terms of general, rather than specific, skills and actions. It is therefore necessary to 


\section{Addendum Proceedings EC-TEL 2007}

start by defining SRL indicators that can guide the search for latent content items. We base our analysis on the characterization of SRL proposed by Zimmermann [14-16], taking into consideration also some subsequent elaborations of his studies $[2,4,12]$ on the potential support to SRL granted by Technology Enhanced Learning Environments. Based on the work of all these authors, we can identify two orthogonal sets of aspects that characterize SRL, that we will call "process" model and "component" model of SRL. The process model views SRL as consisting of three phases that are cyclically repeated during learning activities of self-regulated learners: planning, monitoring and evaluation. The component model, on the other hand, distinguishes among the cognitive (behavioural), meta-cognitive, and motivational/emotional aspects of SRL, both at the individual and at the social level.

Based on these models, and taking into consideration the fact that in VLCs individual activity and social construction of knowledge are strictly intertwined and both very important, we think that SRL indicators to carry out IA in VLCs should concern the following aspects:

- the learners' abilities to plan, monitor and evaluate their own learning process; these can be investigated by spotting the learners' active contribution to: choosing learning objectives and contents, working out or adapting learning strategies; suitably configuring the learning environment; evaluating learning results by comparing one's outcomes with the outcomes of peers and with models possibly provided;

- the learners' abilities to cope with cognitive, meta-cognitive, emotional and motivational challenges imposed by the learning process, throughout the above mentioned phases; these can be captured by identifying clues that show deliberate application of strategies to solve complex problems, to cope with stress and anxiety, to keep up motivation, to relate with peers in a smooth and profitable way;

- the learners' abilities to practice all the above actions both in individual study and in a collaborative learning context, be it face-to-face or at a distance.

The indicators of SRL abilities proposed in this paper derive from this theoretical framework and are shown in Table 1. This table specifies what should be observed into students' messages in order to support the claim that their learning activity is self-regulated. Following Garrison et al. [8], we grouped cognitive with metacognitive aspects since it is often difficult to clearly mark the separation between them, especially in a context, like VLCs, that usually fosters meta-cognitive activities along with cognitive ones. Similarly, we grouped motivational and emotional aspects since the border between the two is quite blurred.

The underlying assumption of this study is that, when a message contains reference to the fact that the sender has carried out a self-regulated action, then we can think that he/she has taken that action, and therefore he/she has practised self-regulation to some extent. For example, let us suppose that a student sends a message commenting on the success of a group activity and another answers by proposing a deadline for the following task. In our approach, we assume that the first student has carried out some kind of self-evaluation and the second has engaged in a form of planning. The opposite, however, can not be claimed, because if a student does not express in his/her messages something that allows us to infer a self-regulation activity, this doesn't mean that self-regulation did not take place, it simply means that the student did not feel the need to express it.

\section{A case study}

We used the selected SRL-indicators to analyse the learning dynamics that took place in part of the online component of a blended teacher training course in educational technology. This course was run in 2005 by ITD-CNR for the Specialization School for Secondary Education of the Liguria region [5]. The course lasted 12 weeks (see course structure in Fig. 1) and involved 95 students and 8 tutors who exchanged, in total, 7605 messages. Among these, the students messages were around $77 \%$ of the total. We selected for this study the activities of Modules 3 and 4,to which we will refer in the following as Activity 1 and Activity 2. We focused in particular on one 
Addendum Proceedings EC-TEL 2007

sub-group of eight students with one tutor. The selected activities lasted 3 weeks each and included a total of 249 messages exchanged, 218 of which by the students.

\begin{tabular}{|c|c|c|c|c|c|c|c|c|c|c|c|}
\hline$\frac{y}{3}-$ & $\sum_{3}^{\frac{1}{2}} \mathrm{~N}$ & $\sum_{3}^{\frac{1}{0}} m$ & $\frac{y}{3}+$ & $\sum_{3}^{\frac{y}{d}} n$ & $\sum_{3}^{\frac{1}{0}} 0$ & $\frac{x}{2}$ & $\sum_{3}^{\frac{y}{8}} \infty$ & $\sum_{3}^{\frac{1}{2}} a$ & $\sum_{3}^{\frac{1}{8}} 0$ & $\frac{\ddot{y}}{3}=$ & $\frac{1}{3} \simeq$ \\
\hline \multicolumn{12}{|c|}{ FACE-TO-FACE } \\
\hline $\begin{array}{c}\mathrm{F} 2 \mathrm{~F} \\
1\end{array}$ & $\begin{array}{c}\mathrm{F} 2 \mathrm{~F} \\
2\end{array}$ & & & & $\begin{array}{c}\mathrm{F} 2 \mathrm{~F} \\
3\end{array}$ & & & $\begin{array}{c}\mathrm{F} 2 \mathrm{~F} \\
4\end{array}$ & & & $\begin{array}{c}\mathrm{F} 2 \mathrm{~F} \\
5\end{array}$ \\
\hline \multicolumn{12}{|c|}{ ONLINE } \\
\hline \multirow{2}{*}{\multicolumn{3}{|c|}{$\begin{array}{c}\text { Mod. } 1 \\
\text { Familiarisation }\end{array}$}} & \multicolumn{2}{|c|}{$\begin{array}{l}\text { Mod.2 } \\
\text { Online } \\
\text { educational } \\
\text { resources }\end{array}$} & \multicolumn{3}{|c|}{$\begin{array}{l}\text { Mod.3 } \\
\text { Web Quests and other } \\
\text { educational uses of the } \\
\text { web }\end{array}$} & \multicolumn{3}{|c|}{$\begin{array}{c}\text { Mod.4 } \\
\text { Collaborative learning } \\
\text { and virtual learning } \\
\text { communities }\end{array}$} & $\begin{array}{l}\text { Mod.5 } \\
\text { Final } \\
\text { activity }\end{array}$ \\
\hline & & & \multicolumn{9}{|c|}{ Transversal Mod.2 - Meta-cognitive reflection } \\
\hline \multicolumn{12}{|c|}{$\begin{array}{c}\text { Transversal Mod.1 } \\
\text { Socialisation }\end{array}$} \\
\hline
\end{tabular}

Fig 1. Structure of the considered course. Interactions were analysed for Modules 3 and 4.

The sample chosen is a good representative of the whole cohort of course participants, in that it has similar characteristics: same ratio between males and females, same mixture of backgrounds, average grade in final assessment very close to the average grade of all the students (see Table 2 for data about the sample). Both the considered activities were based on collaborative learning strategies but involved different ways to organize the group activity. The first was a role play, where students were required to take the role of strongly characterized teachers (e.g. the technology enthusiast, the technology detractor, the bureaucrat, the pragmatist, etc) and to discuss from these different points of view strengths and weaknesses of a WebQuest. The second was a case study on school-based learning communities. Trainees were supposed to discuss pros and cons of a school project recently carried out by a few teachers with their classes. The features of this project were illustrated to the student teachers by its designers and the related documentation (instructional design, students products and assessment results) was made available to them. 
Addendum Proceedings EC-TEL 2007

Table 1 - A taxonomy of indicators of self-regulation

\begin{tabular}{|c|c|c|c|c|}
\hline & & Planning & Execution and Monitoring & Evaluation \\
\hline \multirow{2}{*}{$\begin{array}{l}\text { cognitive and } \\
\text { meta- } \\
\text { cognitive }\end{array}$} & individual & $\begin{array}{l}\text { Code: PCI } \\
\text { - Making plans on how to proceed in the } \\
\text { learning process: breaking up tasks in sub- } \\
\text { tasks, establishing deadlines, detecting } \\
\text { priorities, etc. } \\
\text { - Detecting plan changes necessary to } \\
\text { overcome failures. }\end{array}$ & $\begin{array}{l}\text { Code: MCI } \\
\text { - Enact plans. } \\
\text { - Work consistently on the assigned task. } \\
\text { - Monitoring plan fulfilment. } \\
\text { - Making syntheses of the work done and } \\
\text { objectives reached. }\end{array}$ & $\begin{array}{l}\text { Code: ECI } \\
\text { - Assessing own learning. } \\
\text { - Analysing results, spotting difficulties and } \\
\text { causes of failures. } \\
\text { - Reflecting on individual learning } \\
\text { achieved. } \\
\text { - Comparing one's work with that of peers }\end{array}$ \\
\hline & social & $\begin{array}{l}\text { Code: PCS } \\
\text { - Making proposals on how to proceed in } \\
\text { the learning process. } \\
\text { - Discussing and negotiating on planning } \\
\text { aspects. } \\
\text { - Working out together plan changes } \\
\text { necessary to overcome failures. }\end{array}$ & $\begin{array}{l}\text { Code: MCS } \\
\text { - Quoting peers contributions, asking } \\
\text { questions, reacting to and mediating among } \\
\text { peers. } \\
\text { - Checking understanding } \\
\text { - Summarising the ideas suggested by all } \\
\text { group members. } \\
\text { - Encouraging peers to act. }\end{array}$ & $\begin{array}{l}\text { Code: ECS } \\
\text { - Assessing group learning. } \\
\text { - Commenting group achievements. } \\
\text { - Reflecting on group learning. } \\
\text { - Encouraging peers to express opinions }\end{array}$ \\
\hline \multirow{2}{*}{$\begin{array}{l}\text { motivational } \\
\text { and } \\
\text { emotional }\end{array}$} & individual & $\begin{array}{l}\text { Code: PMI } \\
\text { - Exploring one's expectations about the } \\
\text { current learning activity. } \\
\text { - Anticipating possible emotional aspects. }\end{array}$ & $\begin{array}{l}\text { Code: MMI } \\
\text { - Expressing one's emotions and } \\
\text { motivations } \\
\text { - Looking for appropriate support when } \\
\text { needed }\end{array}$ & $\begin{array}{l}\text { Code: EMI } \\
\text { - Comparing one's current motivation and } \\
\text { emotions with the original ones. } \\
\text { - Understanding the reasons of possible } \\
\text { changes to plans. } \\
\text { - Commenting on emotional aspects } \\
\text { developed during the learning process }\end{array}$ \\
\hline & social & $\begin{array}{l}\text { Code: PMS } \\
\text { - Discussing expectations and motivations } \\
\text { about the current learning activity and } \\
\text { learning in general. } \\
\text { - Sharing motivations for own commitment. } \\
\text { - Encouraging/requesting peers to make } \\
\text { suggestions. }\end{array}$ & $\begin{array}{l}\text { Code: MMS } \\
\text { - Encouraging peers to express their } \\
\text { emotions and motivations. } \\
\text { - Disclosing oneself to peers, } \\
\text { - Encouraging peers and providing them } \\
\text { emotional support. }\end{array}$ & $\begin{array}{l}\text { Code: EMS } \\
\text { - Expressing appreciation for peers' efforts, } \\
\text { contributions and results. } \\
\text { - Spotting group's malfunctioning and } \\
\text { analysing its causes. }\end{array}$ \\
\hline
\end{tabular}


Addendum Proceedings EC-TEL 2007

Table 2 Features of the sample of messages analysed

\begin{tabular}{|c|c|c|c|c|c|}
\hline & \multicolumn{2}{|c|}{ Stud. msgs. } & \multicolumn{2}{c|}{ Tutor msgs. } & Total msgs. \\
\hline & mean & SD & $\mathrm{N}$ & $\%$ & $\mathrm{~N}$ \\
\hline Activity1 & 11,3 & 5,4 & 14 & 13,5 & 104 \\
\hline Activity2 & 11,1 & 17,1 & 17 & 11,7 & 145 \\
\hline
\end{tabular}

Two coders examined all the messages of the sample. One coder had been involved in designing and running the course, while the other was an external rater. After coding, the inter-rater reliability was calculated, in terms of percent agreement, and resulted above $80 \%$ globally. After the computation of the inter-rater reliability, the coders discussed the controversial cases until they reached $100 \%$ agreement. The reported data refer to the agreed coding.

Table 3 reports the inter-rater reliability (Holsti's method). The fact that these values are quite acceptable is a point in favour of the replicability of this investigation approach. The same table shows that the percentage of significant messages was not very high, which might mean that SRL did not take place or it was not detected because students did not always feel the need to express the self-regulated actions they carried out.

Table 3 Sample features in terms of coding results

\begin{tabular}{|l|c|c|c|}
\hline & \multicolumn{2}{|c|}{ Meaningful messages } & \multirow{2}{*}{ Inter-rater reliability } \\
\hline & number & $\%$ & \\
\hline Activity1 & 32 & 35 & 88,6 \\
\hline Activity2 & 49 & 38 & 80,0 \\
\hline
\end{tabular}

Fig.2 shows a comparison of the SRL-related expressions detected by the two coders. Coder 1 ratings are always slightly higher than those produced by Coder 2 , which suggests a more open attitude of Coder 1 rather than a real disagreement on the way to interpret students' messages. This was confirmed by the comparison and discussion of the selected expressions and explains why it was easy to reach a complete agreement after comparing the differences.

The high agreement also suggests it was not difficult to classify the considered messages against the classification grid given in Table 1. This fact is important from the methodological point of view, in relation with the feasibility of the suggested method, since it suggests that the identified SRL-related indicators can be used to carry out a meaningful interaction analysis, even though they refer to latent content.

More accurate measures of the inter-rater reliability were not deemed necessary, given the exploratory nature of this study, which allowed us to compare all selected items and discuss the motivation for their selection. When the study will be extended to a bigger sample of messages, it will be necessary to adopt more advanced measures of reliability, which take into consideration chance agreement [7], along with accurate statistical analysis .

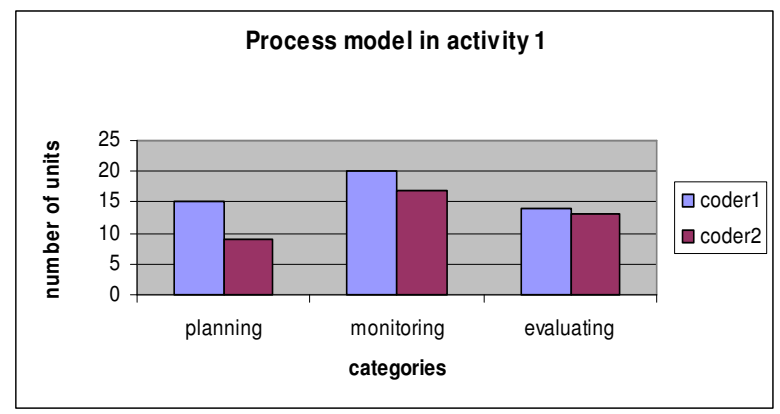

Fig. 2. A comparison of the SRL-indicators detected by the coders for Activity 1. 


\section{Addendum Proceedings EC-TEL 2007}

The chosen unit of analysis was the message. This choice appeared advantageous in that messages are objectively identifiable, their extent is determined by the message authors and they consist of a possibly large but still manageable set of cases. The analysed messages turned out to exhaustively contain all the indicators proposed in Table 1. On the other hand, several messages contained more than one occurrence of the same indicator or of different ones. This made the analysis of the data slightly more difficult to interpret, since, for instance, the percentage of messages containing SRL-related expressions does not give an exact idea of the concentration of indicators detected.

Some quantitative data about the two activities were also considered, such as the number of messages exchanged per day and the contribution of individual students to the discussion. These data helped us gain a global picture of the learning dynamics in the considered activities, but did not provide much information on the development of self-regulation, and therefore will not be reported in this study.

\section{Outcomes of the study}

The main results of the content analysis are reported in Table 4 and Figures 3 to 6. These figures show the raw data, without statistical elaborations on them, since the limited size of the sample analysed makes them more easy to read than complex elaborations. A wider study with more data, on the other hand, would certainly benefit of some statistical elaboration, like inferential statistics. In most cases we will refer to actual number of indicators found rather than percentages, because, as pointed out above, several messages contained more than one indicator, so the concentration of SRL related instances is better represented by the number of instances found rather than the percentage of SRL-related messages. It is useful to remind that the two activities had the same duration, which allowed us to compare the raw data in a meaningful way.

The data in Fig. 3 show that trainees participated more in Activity 2 (the case study) than in Activity 1 (the role play). This is true not only in terms of number of messages, but also as concerns "SRL density". This clearly appears from Table 4, showing that the percentage of SRL-related messages and the average number of indicators per SRL-related message were higher in Activity 2 Also the number of messages exchanged in the second activity was higher (over $42 \%$ more) than in the first one. Activity 1, being a role play, had an inherent plan: once taken a role, the participants were required to adapt their behaviour to the activity constraints and this partially limited their freedom of planning. These data, however, can also support the hypothesis that the students, over the course, were learning to self-regulate themselves. Most likely, both explanations contributed to determine this distribution of SRL occurrences.

Table 4. SRL indicators detected in the two considered activities.

\begin{tabular}{|l|c|c|}
\cline { 2 - 3 } \multicolumn{1}{l|}{} & Activity 1 & Activity 2 \\
\hline total number of students' messages & 90 & 128 \\
\hline number of messages containing SRL indicators & 32 & 49 \\
\hline percentage of SRL related messages & $35,56 \%$ & $38,28 \%$ \\
\hline total number of SRL indicators & 39 & 70 \\
\hline $\begin{array}{l}\text { average number of indicators per SRL-related } \\
\text { message }\end{array}$ & 1,21875 & 1,428571 \\
\hline
\end{tabular}


Addendum Proceedings EC-TEL 2007

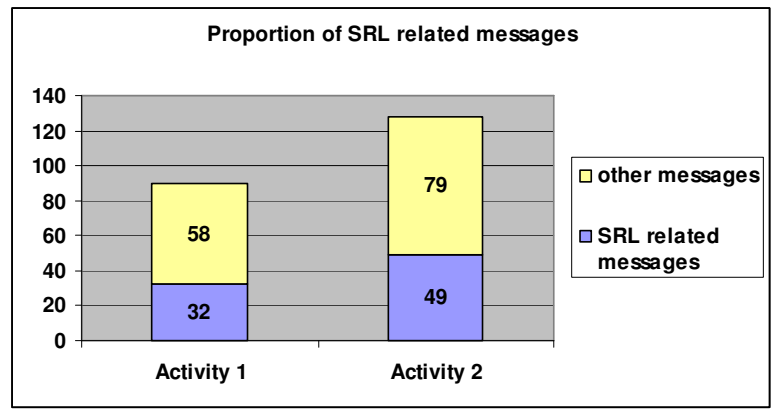

Fig. 3. Number of total messages posted by the students in the two activities and number of messages containing SRL indicators. The number of SRL indicators detected (which does not appear in this figure) is bigger than that of SRL-related messages, since several messages contained more than one indicator.

The limited amount of planning carried out in Activity 1 is confirmed by the data in Fig. 4, where indicators of planning events in this activity are significantly less than those of Activity 2, especially since the difference between the two activities is much more dramatic as concerns planning than the other two phases of SRL. However, Activity 2 shows a higher concentration of SRL-related events also as concerns monitoring and evaluation tasks, which again supports the idea that students generally self-regulated their learning more in this module.

Fig. 5 shows that indicators related to SRL at a social level were definitely more frequent than indicators showing SRL at individual level. Once again, there are two possible reasons behind these data and it is likely that both are partially true. One reason is that VLCs tend to favour the social aspects of SRL more than its individual aspects (for example, students feel encouraged to plan, monitor and evaluate the group work, more than they do with their own individual work). The second explanation is that in online collaborative environments students feel the need to express, when writing messages, the social aspects of their learning activity more than they do with the individual aspects. In other words, they might be planning, monitoring and evaluating their own individual work as well, but they do not feel so much the need to write it in their messages.

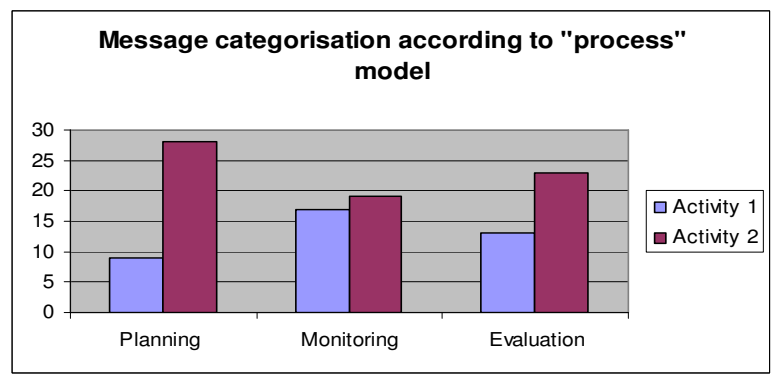

Fig. 4. Coding results according to the categories of the process model

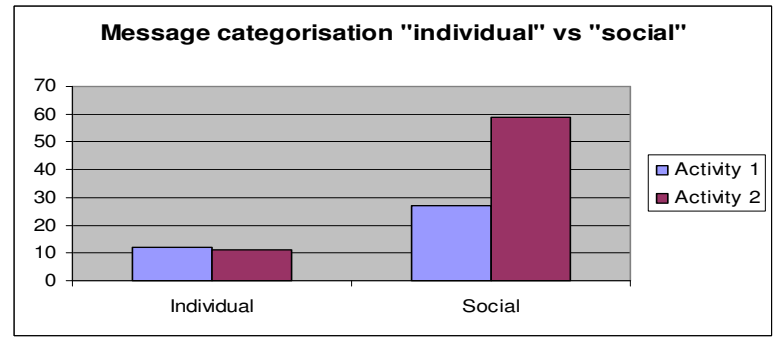

Fig.5. Coding results along the individual vs. social categories

The considerations raising from this analysis are very much in line with the outcomes of a previous study where a different method was used to investigate SRL development in the same course [6]. That study presented the results of a survey 


\section{Addendum Proceedings EC-TEL 2007}

carried out with two questionnaires, one filled in by SRL experts and another by 72 of the 95 trainees taking part in this course. Both concerned the interviewees' opinions about the support received in practicing SRL during the course. The survey showed that the potential of the environment used was deemed valuable especially as concerns the social aspects of SRL: students, as a matter of fact, claimed that they felt a strong social support to their own SRL development from tutors and, even more, from peers.

Fig. 6 shows the message categorization according to the component model. From these data, the cognitive/meta-cognitive level appears to have been supported more than the emotional/motivational one.

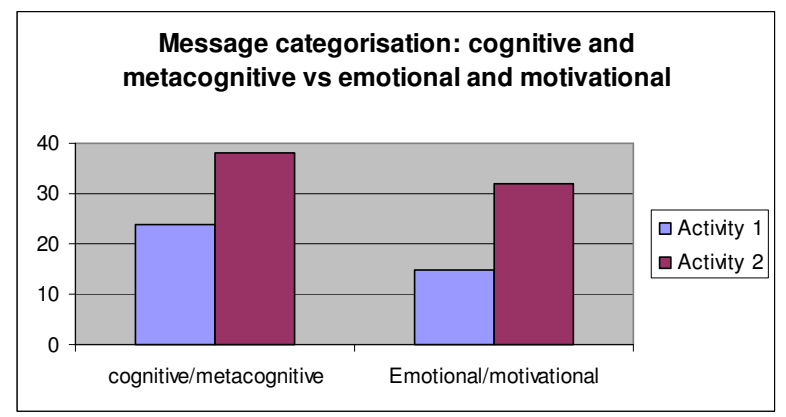

Fig.6. Coding results along the categories cognitive and meta-cognitive vs. emotional and motivational

In the study by Dettori, Giannetti and Persico [6] mentioned above, the comparison of these two categories was the only point of disagreement between the data related to experts' and students' opinions. As shown in Fig. 7, according to SRL experts, the emotional and motivational components of such support were stronger than the cognitive/meta-cognitive ones. According to the trainees, the former was weaker than the latter. This study, and in particular the data shown in Fig. 5, seems to confirm the results based on the students questionnaires..

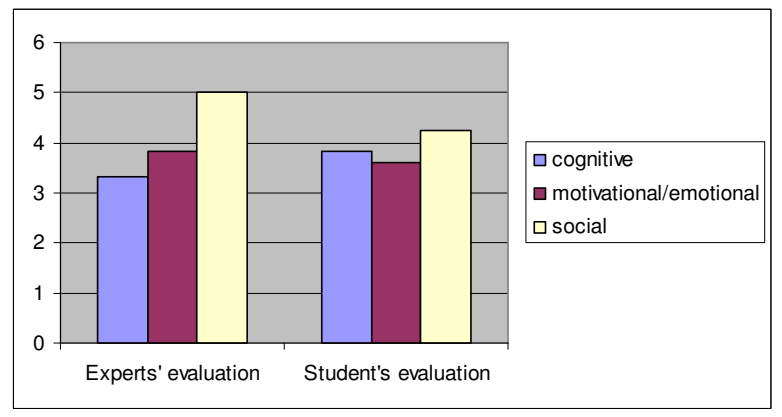

Fig.7. Comparison between the average values obtained from the experts' evaluation and students' evaluation of the same course (from [6]).

\section{Concluding remarks}

The mere presence of SRL-indicators obviously does not prove the development of SRL, but only supports the claim that some particular aspects of SRL were practiced. However, Zimmerman's (1998) studies argue that SRL competence develops through social support and practice, which suggests that repeated practice likely corresponds to improved competence. Increased frequency of the indicators during the learning process can also be regarded as a clue of SRL development. The opposite, however, is not necessarily true: a lack of SRL indicators in students' messages doesn't necessarily mean that the students did not control their learning but simply that they might have not felt the need to make the process explicit in their messages.

This study mostly aims to understand if interaction analysis can provide significant information that could be regarded as complementary to data obtained 


\section{Addendum Proceedings EC-TEL 2007}

with other methods. In general, information about SRL competence is searched by means of interviews with the subjects involved into the learning process, questionnaires and observation. Questionnaires and interviews collect opinions and information reported by the learners or their teachers. On the other hand, observation and content analysis of exchanged messages allow us to analyse directly what students actually did. Messages do not give us access to all that has been taking place in a learning activity, but they allow us to work on data that have not been consciously filtered by the learners while expressing their opinions. Moreover, messages are distributed along the whole duration of a course. This means that we can analyse the evolution of self-regulation over time, which is not possible if such study is made by means of end-of-course questionnaires since these elicit students' opinion when the questionnaire is administered. For all these reasons, we believe that IA is a worthwhile approach, even though labour intensive, in that it appears as a possible valid tool to study SRL in VLCs, useful to complement other methods of analysis.

The features of this study, like the choice to work on a small sample, with a manual method and with limited statistical tools, were determined by its exploratory nature. Its aims were:

- to find out whether content analysis with the selected set of indicators would provide data consistent with previous research;

- to understand whether the method is cost effective and if the indicators are sufficiently well-defined to grant an acceptable reliability;

- to refine the indicators and verify whether there are ways to partially automate the textual analysis process.

As for the first point, according to the collected data, the cost-effectiveness of the approach is encouraging enough to plan an extension of the study to a wider sample and for a longer period, as well as to carry out similar studies in different contexts.

While the answers to the first point are quite satisfactory, the second point appears a bit controversial. The inter-rater reliability, on one side, turned out to be pretty good (at least, percent agreement is acceptable, but for bigger samples it would be worthwhile to use more sophisticated measures of reliability such as Kohen $\mathrm{K}$ (Capozzoli et al, 1999)). SRL-related messages, on the other side, are not a high percentage of the examined ones, and this makes the rating work not very cost effective.

On the third point we can make positive and negative considerations. A positive point is that the indicators' list (Table 1) appeared to be quite complete and apt to classify all the SRL-related situations encountered. Some refinements were made to the indicators list while rating the messages, since readings students' messages allowed us to spot the presence of learning actions which were clearly self-regulated but were missing from our table. Globally the structure and most of the original indicators were fit to the purpose.

As for negative elements, we realized that there is no easy way to automate the analysis process. As a matter of fact, while in many studies focused on manifest content the analysis can be carried out using software tools that look for typical expressions related to the searched clues, in the case of SRL there doesn't seem to be any typical expression that introduce the kind of sentences we are looking for. For instance, planning actions can be introduced by many different expressions, such as "I propose...", "Why don't we...", "We could make/do..." and many others (or their equivalent in other languages). The same holds for monitoring and evaluating sentence patterns: there are so many ways to introduce a sentence where monitoring or evaluation considerations are brought forward, that it appears hardly possible to employ typical text analysis software tools.

To conclude, SRL development can be revealed by a set of "latent variables", and the proposed set of indicators, derived from widely accepted models in the SRL literature, seems to work properly to this purpose. However, there are some important caveat. Firstly, we acknowledge that the use of this kind of variables makes content analysis an inherently subjective and interpretative process. Secondly, researchers who intend to use this method should be aware that what can be found in messages is likely to be true, but it may not provide a complete picture of the phenomenon.

Last but not least, it is widely acknowledged that content analysis is quite a labourintensive research method. As a consequence, a very interesting applied research direction would be to develop Computer Mediated Communication tools that expressly support content analysis, for example by allowing to associate rater's annotations to each message and to compute statistics about them. These tools would 


\section{Addendum Proceedings EC-TEL 2007}

be very useful for content analysts regardless of the aims of the research study they are carrying out.

\section{References}

1. Arbaugh J.B. (2004) Learning to learn online: A study of perceptual changes between multiple online course experiences, Internet and Higher Education 7, pp. 169-182.

2. Banyard P., Underwood J. \& Twiner A. (2006). Do Enhanced Communication Technologies Inhibit or Facilitate Self-regulated Learning?, European Journal of Education, vol. 41(3/4).

3. Capozzoli M., McSweeney L. \& Sinha D. (1999). Beyond kappa: a review of inter-rater agreement measures, The Canadian Journal of Statistics, 27 (1), 3-23.

4 Carneiro R., Steffens K. and Underwood J. (eds.) (2005). Self-regulated Learning in Technology Enhanced Learning Environments, Proceedings of the TACONET Conference. Shaker Verlag, Aachen.

5. Delfino M., Manca S., Persico D. (in print). Harmonizing the online and face-to-face components in a blended course on educational technology.

6. Dettori, G., Giannetti, T. \& Persico, D. (2006). SRL in online cooperative learning: implications for pre-service teacher training, European Journal of Education, vol.41 (3/4), 397-414.

7. De Wever B., Schellens T., Valke M., Van Keer H. (2005) Content Analysis schemes to analyze transcripts of online asynchronous discussion groups: a review, Computers \& Education, vol. 46, 6-28

8. Garrison, D. R., Anderson, T. \& Archer, W. (1999) Critical inquiry in a text-based environment: computer conferencing in higher education, The Internet and Higher Education, 2(2-3), 87-105.

9. Lynch, R. \& Dembo, M. (2004) The relationship between self-regulation and on-line learning in a blended learning context. International review of Research in Open and distance learning, 5, n.2,. Retrieved from http://www.irrodl.org/content/v5.2/lynchdembo.html in Jan. 2006.

10. Potter W. \& Levine-Donnersteirn (1999). Rethinking validity and reliability in content analysis, Journal of Applied Communication Research, 27, 258-284

11. Rourke L., Anderson T., Garrison D.R. \& Archer W. (2001). Methodological Issues in the Content Analysis of Computer Conference Transcripts, International Journal of Artificial Intelligence in Education, vol. 12, 8-22.

12. Steffens K. (2006). Self-Regulated Learning in technology-Enhanced Learning Environments: lessons of a European peer review, European Journal of Education, vol. 41(3/4), pp.353-380.

13. Van den Boom, G., Paas, F., Van Merrienboer, J. J.G. \& Van Gog T. (2004) Reflection prompts and tutor feedback in a web-based learning environments: effects on students' selfregulated learning competence, Computer in Human Behaviour 20, pp. 551-567.

14. Zimmerman B. J. (1998). Developing Self-fulfilling cycles of academic regulation: an analysis of exemplary instructional models. In Shunk and Zimmermann (eds.) Selfregulated learning. From teaching to Self-reflective practice, The Guildford Press, New York, 1-19.

15. Zimmerman B.J. (2000). Attaining self-regulation: a social cognitive perspective. In M. Boekaerts, P. Pintrich, M. Zeidner (eds.), Handbook of self-regulation, (New York, Academic Press) 13-39.

16 Zimmerman B.J. (2001). Theories of self-regulated learning and academic achievement: an overview and analysis, in B. J. Zimmerman \& D. H. Schunk, Self-regulated learning and academic achievement, Mahwah, NJ, Lawrence Erlbaum Associates, 1-37. 